Article

\title{
Water-Air Volatilization Factors to Determine Volatile Organic Compound (VOC) Reference Levels in Water
}

\author{
Vicenç Martí $^{1,2, *}$, Joan De Pablo ${ }^{1,2}$, Irene Jubany ${ }^{2}$, Miquel Rovira ${ }^{2}$ and Emili Orejudo ${ }^{3}$ \\ 1 Universitat Politècnica de Catalunya, Department of Chemical Engineering, ETSEIB, \\ Av. Diagonal, 647, Barcelona E-08028, Spain; E-Mail: joan.de.pablo@upc.edu \\ 2 Fundació CTM Centre Tecnològic, Environmental Technology Area, Plaça de la Ciència, 2, \\ Manresa E-08243, Spain; E-Mails: irene.jubany@ctm.com.es (I.J.); \\ miquel.rovira@ctm.com.es (M.R.) \\ 3 Agència Catalana de l'Aigua, Departament de Territori i Sostenibilitat de la Generalitat de \\ Catalunya, C/Provença, 204-208, Barcelona E-08036, Spain; E-Mail: eorejudo@gencat.cat \\ * Author to whom correspondence should be addressed; E-Mail: vicens.marti@upc.edu; \\ Tel.: +34-93-401-09-57; Fax: +34-93-401-71-50.
}

Received: 3 April 2014; in revised form: 30 May 2014 / Accepted: 3 June 2014 /

Published: 11 June 2014

\begin{abstract}
The goal of this work is the modeling and calculation of volatilization factors (VFs) from water to air for volatile organic compounds (VOCs) in order to perform human health risk-based reference levels (RLs) for the safe use of water. The VF models have been developed starting from the overall mass-transfer coefficients $\left(K_{\text {overall }}\right)$ concept from air to water for two interaction geometries (flat surface and spherical droplets) in indoor and outdoor scenarios. For a case study with five groups of risk scenarios and thirty VOCs, theoretical VFs have been calculated by using the developed models. Results showed that $K_{\text {overall }}$ values for flat and spherical surface geometries were close to the mass transfer coefficient for water $\left(K_{L}\right)$ when Henry's law constant $\left(K_{H}\right)$ was high. In the case of spherical drop geometry, the fraction of volatilization $\left(f_{V}\right)$ was asymptotical when increasing $K_{H}$ with $f_{V}$ values also limited due to $K_{\text {overall }}$. VFs for flat surfaces were calculated from the emission flux of VOCs, and results showed values close to $1000 K_{H}$ for the most conservative indoor scenarios and almost constant values for outdoor scenarios. VFs for spherical geometry in indoor scenarios followed also constant VFs and were far from $1000 K_{H}$. The highest calculated VF values corresponded to the E2A, E2B, E3A and E5A scenarios and were compared with experimental and real results in order to check the goodness of flat and sphere geometry models. Results showed an overestimation of
\end{abstract}


calculated values for the E2A and E2B scenarios and an underestimation for the E3A and E5A scenarios. In both cases, most of the calculated VFs were from 0.1- to 10-times higher than experimental/real values.

Keywords: environmental contaminants; volatile organic compounds; water-air modeling; human health risk assessment; exposure models; volatilization factors

\section{Introduction}

As stated by Water Framework Directive 2000/60/CEE (WFD), contaminated water needs to decrease the concentration of its chemicals with time until reaching a total recovery of a good chemical status, indicating a minimum anthropogenic impact. Under this legislation scope, long-term levels of the concentration of contaminants based on different uses of water cannot be defined.

The new policies derived from WFD need the development of sustainable water management solutions in order to satisfy the demand of the uses of water from people and economic agents (agricultural, domestic, urban, industrial and recreational uses). The application of legislation to waters affected by chemical contamination (e.g., extracted groundwater) could ban its use, but the quality of the impacted water could be good enough for less stringent transitory uses under the scope of admissible risk for human health. In this situation, risk assessment methodologies could be used in order to establish protective reference levels (RLs) [1].

Risk-based soil management is a known methodology able to assess the contamination of a site and defines remediation goals using chemical risk assessment as a base. The methodology includes the exposure assessment, toxicity assessment and target carcinogenic risk and hazard indexes [1,2].

As a part of this methodology, protective levels for the safe use of water (RLs) could be derived by considering a multiple pathway exposure that includes the oral pathway (direct ingestion of water or ingestion of vegetables irrigated with water), dermal pathways (direct dermal contact with water) and the inhalation pathway (inhalation of VOCs in air coming from dissolved VOCs in water) $[3,4]$.

As the calculation of RLs needs a concentration referring to water and the inhalation pathway refers to air, the volatilization factors (VFs) must be introduced and have an important role in the RLs of VOCs.

For soil contamination, there are standard guidelines for risk assessment, where subsurface soil-air, superficial soil-air or groundwater-air VFs have been calculated [5] (pp. 23-30). These VFs assume a constant concentration of the contaminant in water with time, equilibrium partitioning and steady-state transport, no loss of chemicals and steady-state and well-mixed conditions. The calculation of theses VFs start from the equilibrium concentration of the contaminant in the soil-gas phase, and models based on diffusion and advection allow obtaining a vertical flux of contaminants. By applying a mass balance in a hypothetical box or an enclosed space, the calculation of the inhalation concentration in outdoor or indoor scenarios is finally obtained.

In the case of VFs from water to air, there is a lack of these official compilation guidelines to apply for risk assessment studies, but it could be developed with the same approach. The main difference to consider is that for these water-air pathways, the transport of VOCs from water across the liquid and 
gas films and, finally, to air must be integrated to model the overall mass transfer coefficient of these contaminants.

Looking at the water to air pathways that are more common in risk assessment, flat and spherical geometries could be chosen to define the transference of VOCs from flat surfaces (e.g., pools, bathrooms, water extended in soil) [6] (pp. 887-943) or droplets (sprinkler irrigation, shower) [7] (pp. G1-G9).

Several models for the calculation of mass transfer coefficients in water could be applied to calculate these VFs [6] (pp. 908-909). The film model states that the thickness of the limiting layer is independent of the substance. The surface renewal model defines a constant time of renewal for all volatile compounds. The boundary layer model, which is the most used model, introduces the Schmidt number. In the case of air mass transfer, models similar to the boundary layer model could be postulated.

Once the overall mass-transfer has been obtained, the second part of the VFs modeling could be developed in the same way as that for soil contamination. Starting from the fluxes or the emission with time of contaminants, box models [5] (p. 35), [6] (pp. 945-981) could be applied to finally obtain VFs.

A final aspect to consider is the sensitivity of VFs linked to the parameters used to calculate it. Previous works have been focused mainly on several parameters of irrigation [8], but the role of volatility is crucial when considering new VOCs and must be investigated.

This paper develops these mentioned theoretical aspects and applies them to a specific case study that was used to calculate RLs in Catalonia [4] to obtain VFs for several VOCs and to study their volatilization behavior as a function of the volatility $\left(K_{H}\right)$ of the compounds.

\section{Methodology}

\subsection{Mass Transfer Coefficients}

The most used models consider that the equilibrium of water and air in the interface is given by Henry's law. Around this interface, a two-phase as bottleneck boundaries model is considered, with a constant gradient in the narrow zones close to the interface. In this model, the overall mass transfer coefficient, $K_{\text {overall }}\left(\mathrm{m} \cdot \mathrm{s}^{-1}\right)$, for VOCs is given by the mass transfer coefficient for water, $K_{L}\left(\mathrm{~m} \cdot \mathrm{s}^{-1}\right)$, the mass transfer coefficient for air $\left(K_{G}\left(\mathrm{~m} \cdot \mathrm{s}^{-1}\right)\right.$ and $K_{H}$, the non-dimensional Henry's constant law [6] (p. 893), [9] (p. 64):

$$
\mathrm{K}_{\text {overall }}=\frac{1}{\left(\frac{1}{\mathrm{~K}_{\mathrm{L}}}\right)+\left(\frac{1}{\mathrm{~K}_{\mathrm{G}} \cdot \mathrm{K}_{\mathrm{H}}}\right)}
$$

There are several models for mass-transfer coefficients in water and air [6] (p. 912) that could be summarized in the following expression:

$$
K=K_{\text {reference }} \cdot\left(\frac{D}{D_{\text {reference }}}\right)^{a}
$$

$D$ and $D_{\text {reference }}$ are molecular diffusion coefficients $\left(\mathrm{m}^{2} \cdot \mathrm{s}^{-1}\right)$, and $K$ and $K_{\text {reference }}$ are the mass transfer coefficients. The usual way to calculate values of $K_{L}$ and $K_{G}$ is to start from reference values obtained from the evaporation of $\mathrm{H}_{2} \mathrm{O}$ in air or the transport of $\mathrm{CO}_{2}$ in water and to apply several models of proportionality between these reference compounds and each volatility. 
An alternative of molecular diffusion coefficients ratios is to use molecular weight ratios, $\mathrm{M}$ (g/mole), that roughly follow the expression [6] (pp. 803, 813):

$$
\left(\frac{D}{D_{\text {reference }}}\right)=\left(\frac{M}{M_{\text {reference }}}\right)^{-0.5}
$$

The combination of Expressions (2) and (3) allows the calculation in the literature of the overall mass transfer coefficients for flat and spherical surfaces (droplets). These values are adequate for risk assessment scenarios and have been summarized in Table 1.

Table 1. $K_{L}$ and $K_{G}$ values $\left(\mathrm{m} \cdot \mathrm{s}^{-1}\right)$ for flat and spherical geometries.

\begin{tabular}{cccc}
\hline Geometry & $\boldsymbol{K}_{\mathbf{L}}\left(\mathbf{m} \cdot \mathbf{s}^{-1}\right)$ & $\boldsymbol{K}_{G}\left(\mathbf{m} \cdot \mathbf{s}^{-1}\right)$ \\
\hline Flat [6] (p. 915) & $6.5 \cdot 10^{-6} \cdot\left[\frac{D_{w}}{1.488 \cdot 10^{-9}}\right]^{0.67}$ & (4) & $\left.\begin{array}{c}u=0, K_{G, H 2 O}=3 \times 10^{-3} \mathrm{~m} \cdot \mathrm{s}^{-1} \\
2.6 \cdot 10^{-5}\end{array}\right]^{0.67}$ \\
\hline $\begin{array}{c}\text { Sphere }[7,10,11] \\
\text { (p. G-2) }\end{array}$ & $5.55 \cdot 10^{-5} \cdot\left[\frac{[4}{M}\right]^{0.5}$ & $(6)$ & $2.25 \mathrm{~m} \cdot \mathrm{s}^{-1}, K_{G, H 2 O}=8.5 \times 10^{-3} \mathrm{~m} \cdot \mathrm{s}^{-1}$
\end{tabular}

The values for flat geometry are based in the boundary layer model ( $a=0.67$ in Expression (2)) and consider several expressions reviewed in [6] (p. 915). In the case of $K_{L}$, the velocities of water below $4.2 \mathrm{~m} \cdot \mathrm{s}^{-1}$ were considered, and for $K_{G}$, the values depend on the wind velocity. For spherical droplets, values are based in the film model ( $a=1$ in Expression (2)) and are independent of the velocity.

\subsection{Summary of VFs}

The Appendix of the present articles calculates the values of VFs for flat and droplet geometry that are summarized in Table 2. The value, $K_{\text {overall }}$, must be calculated with the adequate values of $K_{L}$ and $K_{G}$ from Table 1. In order to obtain VF values, box models have been used (the room in the indoor scenario and a hypothetical box for outdoor scenarios) for the mass balance of the contaminant. The meaning of the parameters is detailed in the Appendix.

Table 2. Volatilization factor $(\mathrm{VF})$ models $\left(\mathrm{L} \cdot \mathrm{m}^{-3}\right)$ for the types of scenarios considered.

\begin{tabular}{ccccc}
\hline Geometry & \multicolumn{1}{c}{ Indoor } & \multicolumn{2}{c}{ Outdoor } \\
\hline Flat & $\frac{10^{3} \mathrm{~L} \cdot \mathrm{m}^{-3}}{\left(\frac{1}{K_{H}}\right)+\left(\frac{f_{R} \cdot V}{A \cdot K_{\text {overall }}}\right)}$ & $(8)$ & $\frac{10^{3} \mathrm{~L} \cdot \mathrm{m}^{-3}}{\left(\frac{1}{K_{H}}\right)+\left(\frac{u \cdot H}{L \cdot K_{\text {overall }}}\right)}$ & (9) \\
\hline Sphere & $\frac{f_{V} \cdot Q \cdot t_{s h} \cdot\left(10^{3} \mathrm{~L} \cdot \mathrm{m}^{-3}\right)}{V}$ & $(10 \mathrm{a})$ & $\frac{f_{V} \cdot Q \cdot\left(10^{3} \mathrm{~L} \cdot \mathrm{m}^{-3}\right)}{u \cdot H \cdot W}$ & $(11)$ \\
\hline & $\frac{f_{V} \cdot Q \cdot\left(10^{3} \mathrm{~L} \cdot \mathrm{m}^{-3}\right)}{f_{R} \cdot V}$ & $(10 \mathrm{~b})$ & & \\
\hline
\end{tabular}

\subsection{Application to a Case Study}

A case study about the calculation of RLs for the protective use of water in Catalonia is developed in the present work. As a starting point, five groups of risk scenarios (1, agricultural; 2, domestic; 3, urban; 4, industrial; and 5, recreational) were defined (Table 3) [4]. 
Table 3. The pathways included in all of the scenarios considered.

\begin{tabular}{|c|c|c|c|c|c|c|}
\hline & \multirow[b]{2}{*}{ SCENARIOS } & \multirow{2}{*}{$\begin{array}{l}\text { Vegetable } \\
\text { Ingestion }\end{array}$} & \multicolumn{2}{|c|}{ Water } & \multicolumn{2}{|c|}{ Air } \\
\hline & & & Ingestion & $\begin{array}{l}\text { Dermal } \\
\text { Contact }\end{array}$ & Inhalation Indoor & $\begin{array}{c}\text { Inhalation } \\
\text { Outdoor }\end{array}$ \\
\hline E1A & Crop Consumption & Irrigated & & & & \\
\hline E1B & $\begin{array}{l}\text { Indoor irrigation } \\
\text { (e.g., greenhouse) }\end{array}$ & Irrigated & & direct & Sprinkler (sphere) & \\
\hline E1C & $\begin{array}{c}\text { Exterior irrigation } \\
\text { (inundation and sprinkler) }\end{array}$ & Irrigated & & direct & & $\begin{array}{l}\text { Sprinkler (sphere) } \\
\text { Puddle (flat) }\end{array}$ \\
\hline E2A & $\begin{array}{l}\text { Personal hygiene (shower } \\
\text { and hand cleaning) }\end{array}$ & & direct & direct & Shower (sphere) & \\
\hline E2B & $\begin{array}{l}\text { Industrial cleaning (e.g., } \\
\text { cleaning pools) }\end{array}$ & & & direct & $\begin{array}{l}\text { From pool (flat) } \\
\text { Sprinkler (sphere) }\end{array}$ & \\
\hline E3A & $\begin{array}{l}\text { Domestic hygiene (shower } \\
\text { and hand cleaning) }\end{array}$ & & direct & direct & Shower (sphere) & \\
\hline E3B & $\begin{array}{c}\text { Private gardens (irrigation } \\
\text { with sprinkler) }\end{array}$ & & direct & direct & & Sprinkler (sphere) \\
\hline $\mathrm{E} 4 \mathrm{~A}$ & Street cleaning (sprinkler) & & & direct & & Sprinkler (sphere) \\
\hline E4B & Urban cleaning (sprinkler) & & & direct & Sprinkler (sphere) & \\
\hline E5A & Recreational bath (pools) & & direct & direct & From pool (flat) & \\
\hline
\end{tabular}

Table 4. Volatilization parameters for indoor scenarios.

\begin{tabular}{cccccccc}
\hline Parameter & E1B & E2A & E2B Flat & E2B sph/E4B & E3A & E5A & Reference \\
\hline$f_{R}\left(\mathrm{~s}^{-1}\right)$ & $2.3 \times 10^{-3}$ & - & $2.3 \times 10^{-3}$ & $2.3 \times 10^{-3}$ & - & $1.4 \times 10^{-3}$ & {$[5](\mathrm{p} .28)$} \\
$V\left(\mathrm{~m}^{3}\right)$ & 300 & 4.5 & - & 1250 & 4.5 & - & Calculated \\
$V / A(\mathrm{~m})$ & - & - & 3 & - & - & 2 & {$[5](\mathrm{p} .28)$} \\
$t_{\text {travel }}(\mathrm{s})$ & 10 & 0.64 & - & 0.64 & 0.64 & - & {$[12]$} \\
$d(\mathrm{~m})$ & $2 \times 10^{-3}$ & $2 \times 10^{-3}$ & - & $2 \times 10^{-3}$ & $1 \times 10^{-3}$ & - & {$[12]$} \\
$Q \cdot 10^{5}\left(\mathrm{~m}^{3} \cdot \mathrm{s}^{-1}\right)$ & 5.55 & 16.6 & - & 50 & 16.6 & - & {$[7,12]$} \\
$t_{\text {sh }}(\mathrm{s})$ & - & 600 & - & - & 600 & - & {$[9]$} \\
\hline
\end{tabular}

Table 5. Volatilization parameters for outdoor scenarios.

\begin{tabular}{cccccc}
\hline Parameter & E1C Flat & E1C sph & E3B & E4A & References \\
\hline$u\left(\mathrm{~m} \cdot \mathrm{s}^{-1}\right)$ & 2.25 & 2.25 & 2.25 & 2.25 & {$[5]$ (p. 28) } \\
$H(\mathrm{~m})$ & 1.5 & 2.5 & 2 & 2 & {$[5]$ (p. 28) and calculated } \\
$L(\mathrm{~m})$ & 15 & - & - & - & {$[5](\mathrm{p} .28)$} \\
$t_{\text {travel }}(\mathrm{s})$ & - & 10 & 0.64 & 0.64 & {$[12]$} \\
$d(\mathrm{~m})$ & - & $2 \times 10^{-3}$ & $2 \times 10^{-3}$ & $2 \times 10^{-3}$ & {$[12]$} \\
$Q \cdot 10^{5}\left(\mathrm{~m}^{3} \cdot \mathrm{s}^{-1}\right)$ & - & 50 & 50 & 183 & {$[7,12]$} \\
$W(\mathrm{~m})$ & - & 18 & 8 & 8 & Local data \\
\hline
\end{tabular}

Each scenario was divided into several sub-scenarios that included as pathways the ingestion of vegetables irrigated with water, the ingestion of water (shower, sprinkler), the inhalation of volatiles and dermal contact with water (shower, contact with sprinklers). 
In the last two columns of Table 3 (indoor and outdoor), the detail of the type of geometry needed is included. Table 4 compiles the parameters for the indoor scenarios to calculate VF and Table 5 the parameters for outdoor scenarios. In both cases, the references of these values are given.

The VOCs considered and their chemical properties ( $M$, dimensionless $K_{H}, D_{a}$ and $\left.D_{w}\right)$ are shown in Table 6 and have been obtained from the RAIS (Risk Assessment Information System) database [13], with the exception of MTBE, ETBE and tetrahydrofuran, which were obtained from the GSI database [14]. The rank of $K_{H}$ indicates the order of $K_{H}$ of the VOCs classified from lower to higher values, and it will be helpful to identify individual VOCs in Figures 1-5.

Table 6. The properties of the VOCs for VF calculation.

\begin{tabular}{|c|c|c|c|c|c|}
\hline & $M\left(g \cdot\right.$ mole $\left.^{-1}\right)$ & $K_{H}$ & $D_{a}\left(\mathrm{~m}^{2} \cdot \mathrm{s}^{-1}\right)$ & $D_{w}\left(\mathrm{~m}^{2} \cdot \mathrm{s}^{-1}\right)$ & $\operatorname{Rank} K_{H}$ \\
\hline Acetone & $5.81 \times 10^{1}$ & $1.62 \times 10^{-3}$ & $1.24 \times 10^{-5}$ & $1.14 \times 10^{-9}$ & 2 \\
\hline Benzene & $7.81 \times 10^{1}$ & $2.27 \times 10^{-1}$ & $8.80 \times 10^{-6}$ & $9.80 \times 10^{-10}$ & 18 \\
\hline Bromoform & $2.53 \times 10^{2}$ & $2.19 \times 10^{-2}$ & $1.49 \times 10^{-6}$ & $1.03 \times 10^{-9}$ & 7 \\
\hline Butanone, 2- & $7.21 \times 10^{1}$ & $2.33 \times 10^{-3}$ & $8.08 \times 10^{-6}$ & $9.86 \times 10^{-10}$ & 3 \\
\hline Carbon Tetrachloride & $1.54 \times 10^{2}$ & $1.13 \times 10^{0}$ & $7.30 \times 10^{-6}$ & $8.70 \times 10^{-10}$ & 29 \\
\hline Chlorobenzene & $1.13 \times 10^{2}$ & $1.27 \times 10^{-1}$ & $1.04 \times 10^{-5}$ & $1.00 \times 10^{-9}$ & 13 \\
\hline Chloroform & $1.19 \times 10^{2}$ & $1.50 \times 10^{-1}$ & $1.04 \times 10^{-5}$ & $9.90 \times 10^{-10}$ & 15 \\
\hline Dichloroethylene, 1,1 & $9.69 \times 10^{1}$ & $1.07 \times 10^{0}$ & $1.01 \times 10^{-5}$ & $1.17 \times 10^{-9}$ & 28 \\
\hline Dichloroethylene, c-1,2 & $9.69 \times 10^{1}$ & $1.67 \times 10^{-1}$ & $9.00 \times 10^{-6}$ & $1.04 \times 10^{-9}$ & 16 \\
\hline Dichloromethane & $8.49 \times 10^{1}$ & $1.33 \times 10^{-1}$ & $7.36 \times 10^{-6}$ & $1.13 \times 10^{-9}$ & 14 \\
\hline Dichloromethane, 1,2 & $9.90 \times 10^{1}$ & $4.82 \times 10^{-2}$ & $7.07 \times 10^{-6}$ & $1.19 \times 10^{-9}$ & 10 \\
\hline Dichloroethylene, $\mathrm{t}-1,2$ & $9.69 \times 10^{1}$ & $3.83 \times 10^{-1}$ & $6.95 \times 10^{-6}$ & $7.34 \times 10^{-10}$ & 24 \\
\hline ETBE & $1.02 \times 10^{2}$ & $9.99 \times 10^{-2}$ & $7.50 \times 10^{-6}$ & $7.80 \times 10^{-10}$ & 12 \\
\hline Ethylbenzene & $1.06 \times 10^{2}$ & $3.22 \times 10^{-1}$ & $1.78 \times 10^{-5}$ & $1.98 \times 10^{-9}$ & 23 \\
\hline Formaldehyde & $3.00 \times 10^{1}$ & $1.38 \times 10^{-5}$ & $5.42 \times 10^{-6}$ & $5.91 \times 10^{-10}$ & 1 \\
\hline Hexachlorobenzene & $2.85 \times 10^{2}$ & $6.95 \times 10^{-2}$ & $7.92 \times 10^{-6}$ & $9.41 \times 10^{-9}$ & 11 \\
\hline MTBE & $8.81 \times 10^{1}$ & $2.44 \times 10^{-2}$ & $5.90 \times 10^{-6}$ & $7.50 \times 10^{-10}$ & 8 \\
\hline Naphthalene & $1.28 \times 10^{2}$ & $1.80 \times 10^{-2}$ & $7.10 \times 10^{-6}$ & $7.90 \times 10^{-10}$ & 6 \\
\hline Tetrachloroethane & $1.68 \times 10^{2}$ & $1.50 \times 10^{-2}$ & $7.20 \times 10^{-6}$ & $8.20 \times 10^{-10}$ & 5 \\
\hline Tetrachloroethylene & $1.66 \times 10^{2}$ & $7.24 \times 10^{-1}$ & $7.80 \times 10^{-6}$ & $8.80 \times 10^{-10}$ & 27 \\
\hline Tetrahydrofuran & $7.21 \times 10^{1}$ & $5.75 \times 10^{-3}$ & $9.30 \times 10^{-6}$ & $9.88 \times 10^{-10}$ & 4 \\
\hline Toluene & $9.21 \times 10^{1}$ & $2.71 \times 10^{-1}$ & $8.70 \times 10^{-6}$ & $8.60 \times 10^{-10}$ & 19 \\
\hline Trichloroethane, 1,1,1 & $1.33 \times 10^{2}$ & $7.03 \times 10^{-1}$ & $7.80 \times 10^{-6}$ & $8.80 \times 10^{-10}$ & 26 \\
\hline Trichloroethane, $1,1,2$ & $1.33 \times 10^{2}$ & $3.37 \times 10^{-2}$ & $7.80 \times 10^{-6}$ & $8.80 \times 10^{-10}$ & 9 \\
\hline Trichloroethylene & $1.31 \times 10^{2}$ & $4.03 \times 10^{-1}$ & $7.90 \times 10^{-6}$ & $9.10 \times 10^{-10}$ & 25 \\
\hline Trichlorofluoromethane & $1.37 \times 10^{2}$ & $3.97 \times 10^{0}$ & $8.70 \times 10^{-6}$ & $9.70 \times 10^{-10}$ & 30 \\
\hline xylene, $\mathrm{m}$ - & $1.06 \times 10^{2}$ & $2.94 \times 10^{-1}$ & $7.00 \times 10^{-6}$ & $7.80 \times 10^{-10}$ & 22 \\
\hline xylene, o- & $1.06 \times 10^{2}$ & $2.12 \times 10^{-1}$ & $8.70 \times 10^{-6}$ & $1.00 \times 10^{-9}$ & 17 \\
\hline xylene, $\mathrm{p}$ - & $1.06 \times 10^{2}$ & $2.82 \times 10^{-1}$ & $7.69 \times 10^{-6}$ & $8.44 \times 10^{-10}$ & 21 \\
\hline xylenes (average) & $1.06 \times 10^{2}$ & $2.71 \times 10^{-1}$ & $7.14 \times 10^{-6}$ & $9.34 \times 10^{-10}$ & 20 \\
\hline
\end{tabular}




\section{Results and Discussion}

\subsection{Mass-Transfer Coefficients}

Figure 1 shows the values of $K_{\text {overall }}$ as a function of $K_{H}$ for the studied contaminants by using the models in Table 1. $K_{H}$ for relevant contaminants is marked in red with small letters detailed in the caption of Figure 1. BTEX refers to benzene, toluene, ethylbenzene and xylene, all with similar volatility.

Figure 1. Overall mass-transfer coefficients as a function of $K_{H}$. a-Naphthalene, b-hexachlorobenzene, c-chloroform-dichloromethane, d-BTEX (benzene, toluene, ethylbenzene and xylene), e-trichloroethylene-tetrachloroethylene, f-carbon tetrachloride.

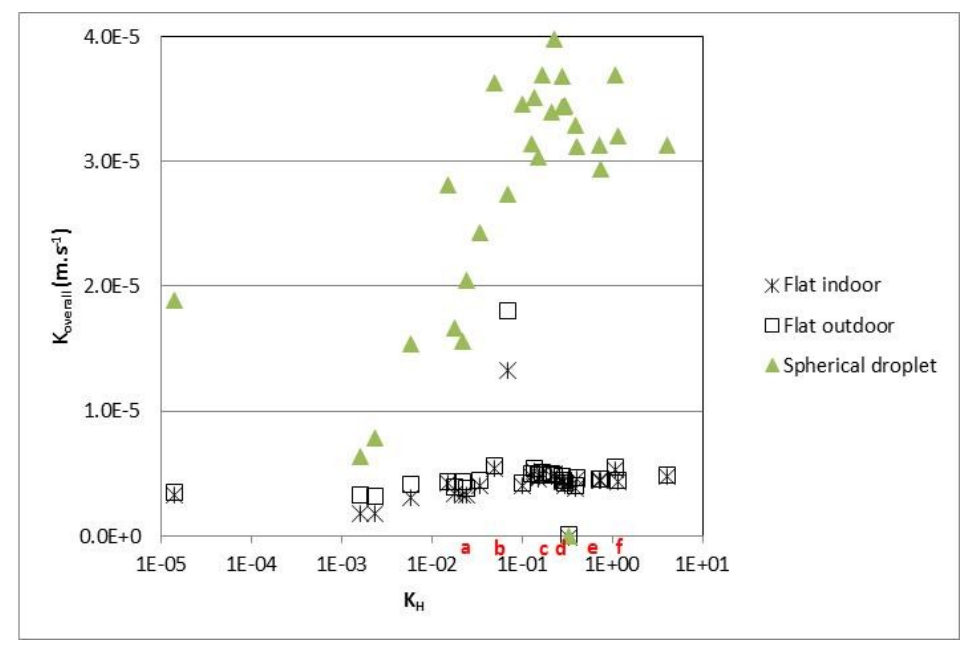

As can be seen, as a general trend, VOCs with a $K_{H}$ above $10^{-1}$ have an asymptotic value of $K_{\text {overall }}$. Expression (1) shows that for very volatile compounds, the water mass-transfer limits the overall mass-transfer; thus, $K_{\text {overall }}$ is approximately $K_{L}$ for most of the studied compounds.

As $K_{L}$ has the same model for flat geometry for outdoor and indoor scenarios, both types of values match. Most of the contaminants have also a similar $D_{w}$ value, and thus, an asymptotic value of $5 \times 10^{-6} \mathrm{~m} \cdot \mathrm{s}^{-1}$ could be used as $K_{\text {overall }}$ to assess these scenarios. The outlier in the graphic of flat models is MTBE, probably due to an error of $D_{w}$ in the database.

In the case of spherical geometry, the overall transference is higher than in the flat surface, due to the falling of the droplets. Asymptotical values are also close to $K_{L}$, but the dependence now is due to $\mathrm{M}$ and values between $3 \times 10^{-5} \mathrm{~m} \cdot \mathrm{s}^{-1}$ and $4 \times 10^{-5} \mathrm{~m} \cdot \mathrm{s}^{-1}$.

\subsection{Fraction of Volatilization}

In the case of spherical droplets, the fraction of volatilization $\left(f_{V}\right)$ for three groups of scenarios (E1B and E1C; a group formed by E2A, E2B, E3B, E4A and Scenario E3A has been calculated. These groups are formed because they share the same parameters than influence $f_{V}$ (see Tables 4 and 5). Results are shown in Figure 2. As these scenarios have a limited $K_{\text {overall }}$, the fraction of volatilization is also limited to a maximum, but never reaches one. Agricultural scenarios, where the time of travel has been considered as higher, show fractions around $60 \%-70 \%$ for volatiles with $K_{H}$ greater than $10^{-2}$. 
Figure 2. The fraction of volatilization for droplets as a function of $K_{H}$.

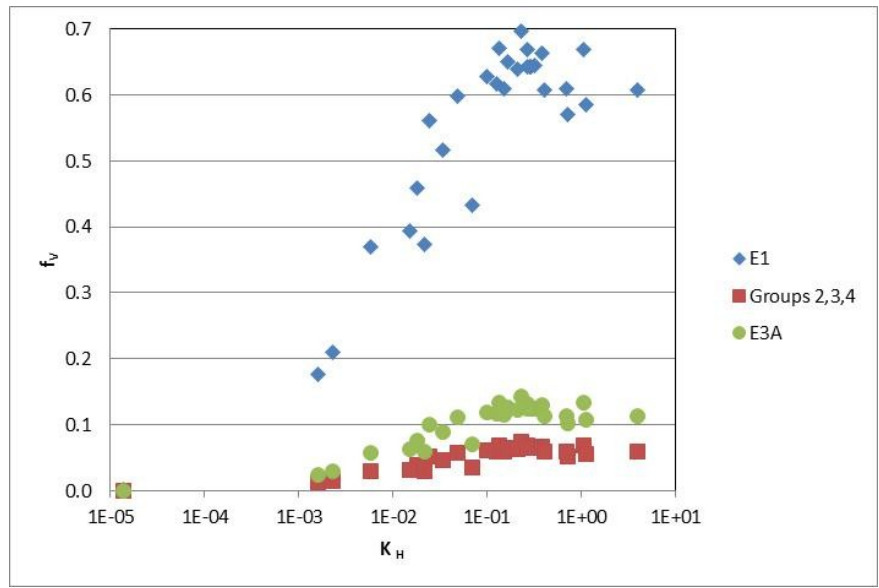

In the case of showers and irrigation, where a dropping time from two meters $(0.64 \mathrm{~s})$ and a diameter of $1 \mathrm{~mm}$ (Scenario E3A) or $2 \mathrm{~mm}$ (Groups 2-4) has been considered, the fraction of volatilization is around $6 \%$ to $12 \%$.

\subsection{VFs for Flat Geometries}

VFs for flat geometry (Scenarios E2B, E5A and E1C) were calculated with the expressions of Table 2 and the data from Tables 4-6.

In Figure 3, VFs are plotted as a function of $K_{H}$ and are compared with 1,000 times $K_{H}$, which would have the equivalent units of $\mathrm{L} \cdot \mathrm{m}^{-3}$.

Figure 3. VFs as a function of $K_{H}$ for flat geometry.

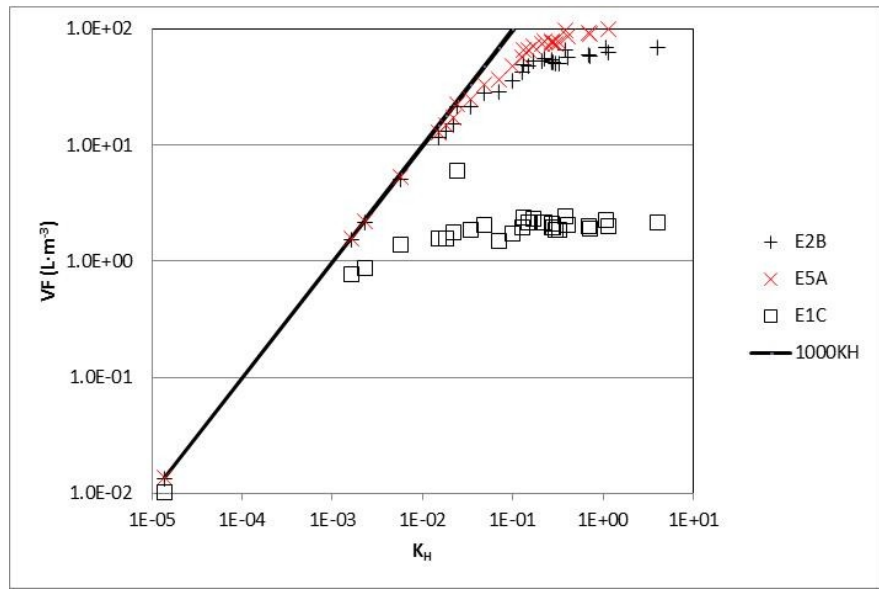

For indoor scenarios and $K_{H}$ below $10^{-2}$, VFs could be estimated as $1000 K_{H}$. For higher values of $K_{H}$, the full expression has to be employed, as asymptotic values are not yet reached. On the contrary, for outdoor scenarios, the asymptotic value (around $2 \mathrm{~L} \cdot \mathrm{m}^{-3}$ ) is obtained for most of the compounds when $K_{H}$ is higher than $10^{-2}$. This concept of limited VFs for volatiles follows Andelman's model [15], which establishes a VF $=0.5 \mathrm{~L} \cdot \mathrm{m}^{-3}$ when $K_{H}$ exceeds $4 \times 10^{-4}$. 


\subsection{VFs for Spherical Geometries}

Figure 4 shows the VFs values for the indoor scenarios (E1B, E2A, E2B, E3A and E4B). In all cases, for volatilities greater than $10^{-2}$, asymptotical values (that correspond to the asymptotical values of $f_{V}$ ) were obtained. From the two indoor scenarios, the model without the renovation of air is more conservative, because $t_{s h}$ is greater than the inverse of $f_{R}$. Values equivalent to $K_{H}$ are only obtained when volatility is very low and for Scenarios E2A and E3A. The flow rate, the volume of the room and the renovation or time of the shower are, thus, the main parameters that will influence these VFs.

Figure 4. VFs for indoor scenarios as a function of $K_{H}$ for spherical droplets geometry.

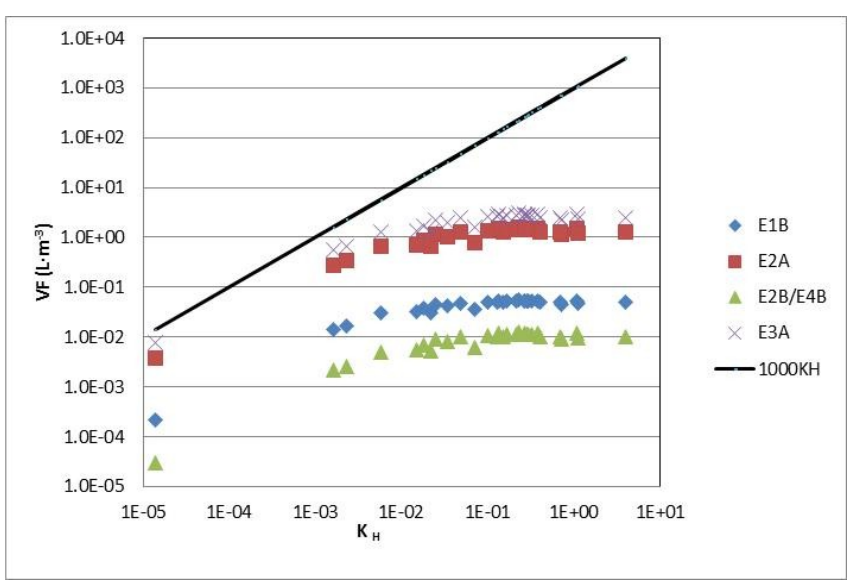

In the case of outdoor scenarios (E1C, E2B and E4A), Figure 5 shows also steady values for high volatile compounds, but the values are very far from the $K_{H}$ values, as the renovation in the outdoor scenario is very high.

Figure 5. VFs for outdoor scenarios as a function of $K_{H}$ for spherical droplet geometry.

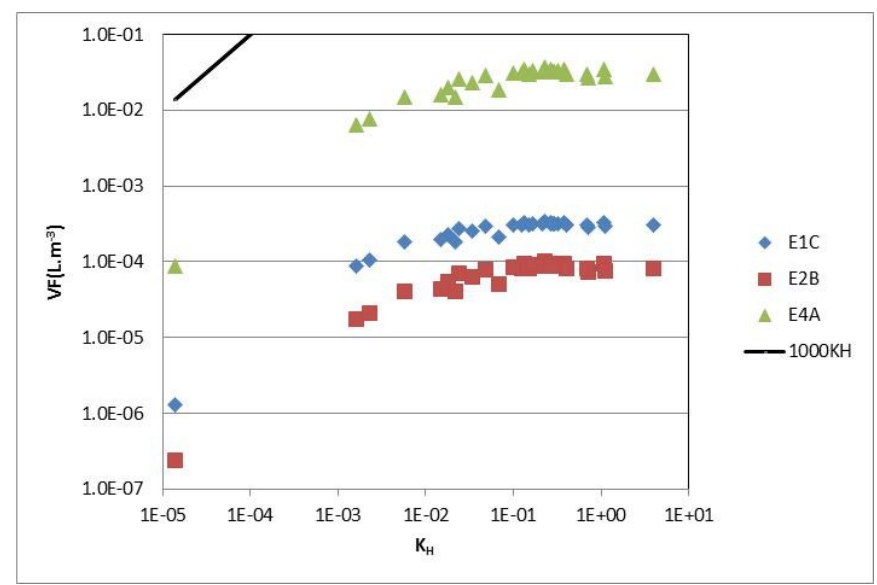

The flow rate, the fraction of volatilization and the width of the zone are important parameters that influence VF, as can be seen in Table 2. 


\subsection{Comparison with Experimental/Real VFs Values}

The highest VFs correspond to Scenarios E2B and E5A for flat geometries and E2A and E3A for sphere (drop) geometries. In these scenarios, the role of VFs in RLs is very important, and thus, a review of these values is needed to check if values are overestimated or underestimated.

Table 7 summarizes some experimental VFs and $f_{v}$ obtained from the reviewed references linked to HHRA scenarios [16]. The table also includes VFs for chloroform obtained from the measured concentration in swimming pools reviewed in [17]. References have been chosen with temperatures of water ranging from 20 to $30{ }^{\circ} \mathrm{C}$ in all cases. These temperatures are representative of annual exposure to water and are the temperatures of reference for the $K_{H}$ given in Table 6 . In the table, n means the number of experiments performed in each reference to obtain the values.

Table 7. Experimental indoor VFs and $f_{V}$ for VOCs.

\begin{tabular}{ccccccc}
\hline & $\boldsymbol{T}\left({ }^{\circ} \mathbf{C}\right)$ & $\begin{array}{c}\text { Model, Scenarios } \\
\text { Representative }\end{array}$ & $\begin{array}{c}\mathbf{V F} \\
\left(\mathbf{L} \cdot \mathbf{m}^{-3}\right)\end{array}$ & $\boldsymbol{f}_{\boldsymbol{V}}$ & $\boldsymbol{n}$ & Refs. \\
\hline Acetone & $23-24$ & Flat, E2B, E5A & $0.44-0.46$ & $0.049-0.058$ & 2 & {$[18]$} \\
Toluene & $23-24$ & Flat, E2B, E5A & $3.6-5$ & $0.29-0.31$ & 2 & {$[18]$} \\
Ethylbenzene & $23-24$ & Flat, E2B, E5A & $3.1-4.6$ & $0.31-0.33$ & 2 & {$[18]$} \\
Chloroform & $20-30$ & Flat, E2B, E5A & $1.4-21.4$ & - & $4-70$ & {$[17,19-22]$} \\
Acetone & $21-22$ & Drop, E2A, E3A & $0.83-1.3$ & $0.063-0.093$ & 4 & {$[23]$} \\
Ethylbenzene & $21-23$ & Drop, E2A, E3A & $1.5-4.8$ & $0.58-0.63$ & 4 & {$[23]$} \\
Toluene & $21-24$ & Drop, E2A, E3A & $4.1-9.1$ & $0.58-0.64$ & 4 & {$[23]$} \\
Trichloroethylene & $21-27$ & Drop, E2A, E3A & $15-88$ & $0.44-0.57$ & 4 & {$[24]$} \\
Chloroform & $26-29$ & Drop, E2A, E3A & $3.5-18$ & $0.46-0.52$ & 4 & {$[24]$} \\
Trichloroethylene & $21-22$ & Drop, E2A, E3A & $54-103$ & $0.50-0.67$ & 2 & {$[25]$} \\
\hline
\end{tabular}

VFs from flat geometry scenarios (E2B and E5A) have been compared with reference [18], which worked with the example of a bath with surface volatilization. In this reference, the ratio surface of water to the air flow-rate is similar to the E2B scenario and half of the E5A scenario. Other important sources to calculate real VFs are the concentrations of chloroform in air and water in swimming pools [17,19-22]. Though the parameters behind these real values are unknown in these references, they offer a realistic approach for the expected VFs in recreational and industrial indoor pools.

Comparing VF from Table 7 with the values of Figure 3, it can be seen that acetone, toluene and ethylbenzene have been overestimated in our study, with values that are close to $1000 K_{H}$. This overestimation is less than ten times for acetone and around ten times for ethylbenzene and toluene. In the case of chloroform in pools, the range of VFs reviewed in Table 7 is $2-20$ times below the calculated VFs and, thus, is also overestimated.

For scenarios with drop geometry in showers (E2A and E3A), several references in Table 7 have been used. Based on the water flow-rate to air flow-rate ratio, [23] is the most representative of E2A and E3A. Another reference [24] covers scenarios that are from one- to 20-times more conservative than E2A and E3A, and [25] uses scenarios three- and 20-times more conservative.

As can be seen in Table 7, the fraction of volatilization measured in all cases is around 4-5-times higher than the modeled in E2A and E3A (Figure 2). This is probably due to the use of a travel time 
( $\left.t_{\text {travel }}\right)$ equal to the flight time $(0.64 \mathrm{~s})$ instead, considering the flight time plus the time remaining in the floor of the shower. When this time is increased to $10 \mathrm{~s}$ (Scenario E1B), the fraction of volatilization reaches the values reported in Table 7.

When comparing VFs, it could be seen that that acetone and toluene ethylbenzene in [23] have been underestimated about 5-10-times in our study. This underestimation is linked to the use of low travel time. In Table 7, [24] uses scenarios that are more conservative, but one experiment is similar to E2A and E3A with a VF of around $15\left(\mathrm{~L} \cdot \mathrm{m}^{-3}\right)$ for trichloroethylene and chloroform, which means values 10 -times higher than the values of the present study.

\section{Conclusions}

VFs of VOCs for several scenarios could be easily calculated applying the mass-transfer from water to air concept combined with flat and spherical geometries. The $K_{\text {overall }}$ is limited to $K_{L}$ and also limits $f_{v}$ for all of the volatiles studied.

As a general rule, this situation implies that VFs for high-volatility VOCs reach a limit value that is a function of $K_{L}$ and other parameters from Table 2, excluding $K_{H}$. On the contrary, low volatility VOCs in indoor scenarios could reach values equivalent to $K_{H}$, and the parameters of Table 2 have less relevance for defining VFs.

High VF values become relevant for RLs and for risk assessment case studies, as this means that inhalation is the most important pathway that contributes to the risk. In the present work, the comparison of the highest values of VFs and $f_{V}$ from the present work with experimental values from other references has shown that VFs for flat geometries are overestimated for Scenarios E2B and E5A and underestimated for E2A and E3A. In all of the modeled VFs, the values are around the same order of magnitude as the references with similar hypothesis. The underestimation is mainly due to the use of low travel times for the drop. This means that this parameter could be improved, including not only the flight time, but also the time remaining in the shower.

\section{Acknowledgments}

Special thanks should be given to Agencia Catalana de l'Aigua for the funding received for the present work. The authors want to thank Alicia Rubalcaba, as well as David López for all of his support for the elaboration of the results. The reviewers are also acknowledged for their comments, which significantly improved the quality of the original manuscript.

\section{Author Contributions}

Vicenç Martí developed all the modeling, coordinated the calculation of VFs and redacted the core of the present article, Emili Orejudo suggested the list of contaminants, scenarios and parameters of scenarios, Joan De Pablo, Irene Jubany and Miquel Rovira suggested the general approach and reviewed the process of calculation and results. 


\section{Appendix-Theoretical Expressions for VFs (Table 2)}

\section{A.1. Flat Surface}

As this overall coefficient refers to the resistances between the layers of water with a concentration, $C\left(\mathrm{mg} \cdot \mathrm{L}^{-1}\right)$, and the layer with an air concentration, $C_{a}\left(\mathrm{mg} \cdot \mathrm{m}^{-3}\right)$, the flux of contaminant from a flat surface could be defined as [6] (p. 896):

$$
q=\mathrm{K}_{\text {overall }} \cdot\left[1000 C-\frac{C_{a}}{K_{H}}\right]
$$

This flux, $q\left(\mathrm{mg} \cdot \mathrm{m}^{-2} \cdot \mathrm{s}^{-1}\right)$, is assumed to be constant with time (constant source concentration and steady-state hypotheses).

For the case of the indoor scenario, a flat surface of contaminated water $A\left(\mathrm{~m}^{2}\right)$ in a perfectly-mixed room of volume $V\left(\mathrm{~m}^{3}\right)$ that has a frequency of renovation of air, $f_{R}\left(\mathrm{~s}^{-1}\right)$, has been considered. Under these conditions, the concentration, $C_{a F I}$, is given by [5] (p. 35):

$$
C_{a F I}=\frac{q_{F I} \cdot A}{V \cdot f_{R}}
$$

Combining Expressions (A1) and (A2.), the volatilization factor for this case could be obtained, and the final expression is compiled in Table 2 (Expression (8)).

In an outdoor scenario, the box model could be applied, and the maximum estimated concentration in air inside the box is a function of $L(m)$, the length of contaminated water in the direction of the wind that blows with speed $u\left(\mathrm{~m} \cdot \mathrm{s}^{-1}\right)$ and the height $H(\mathrm{~m})$ of the box [5] (p. 35).

$$
C_{a F E}=\frac{\mathrm{q}_{F E} \cdot L}{u \cdot H}
$$

Combining Expressions (A1) and (A3), the VF could be obtained for flat source and indoor scenario, and the final expression is compiled in Table 2 (Expression (9)).

\section{A.2. Spherical Droplets}

In the case of the volatile release of VOCs from spherical droplets to air, the variation of the concentration in the droplet is given by the first-order process that is a function of the overall mass transfer coefficient given in Equation (2) and $a\left(\mathrm{~m}^{2} \cdot \mathrm{m}^{-3}\right)$ that is the specific surface of the droplet. For the spheres, $a=6 / d$, where $d(\mathrm{~m})$ is the diameter of the drop.

$$
\frac{d C}{d t}=-K_{\text {overall }} \cdot a \cdot C
$$

The most important parameter in this model is the fraction of volatilization, $f_{V}$, which expresses the amount of volatiles released from the droplet to air. This parameter could be easily obtained integrating Expression (A4).

$$
f_{v}=1-\exp \left(\frac{-6 \cdot \mathrm{K}_{\text {overall }}^{\prime} \cdot t_{\text {travel }}}{d}\right)
$$

The time, $t_{\text {travel }}$, is the equivalent time of travel of the droplet (flying and remaining before going to the sink). The amount of VOC released could be expressed from this volatilization fraction, the flow of water used in the shower or irrigation, $Q\left(\mathrm{~m}^{3} \cdot \mathrm{s}^{-1}\right)$ and $C\left(\mathrm{mg} \cdot \mathrm{L}^{-1}\right)$. 
For indoor scenarios, two models could be considered to calculate the concentration in air. If it is assumed that there is no renovation of air in the bathroom, the concentration, $C_{a S I}^{\prime}\left(\mathrm{mg} \cdot \mathrm{m}^{-3}\right)$, will be linear with the time of showering, $t_{s h}(\mathrm{~s})$.

$$
C^{\prime}{ }_{a S I}=\frac{\mathrm{f}_{V} \cdot Q \cdot C \cdot t_{s h}}{V}
$$

In the second model, there is a renovation frequency of the volume of the bathroom. Under this consideration, the steady-state concentration in the air, $C_{a S I}\left(\mathrm{mg} \cdot \mathrm{m}^{-3}\right)$, of the bathroom will be given by:

$$
C_{a S I}=\frac{\mathrm{f}_{V} \cdot Q \cdot C}{V \cdot f_{R}}
$$

For outdoor scenarios, a similar approach could be used, and the concentration, $C_{a S E}\left(\mathrm{mg} \cdot \mathrm{m}^{-3}\right)$, will be obtained as:

$$
C_{\text {aSE }}=\frac{\mathrm{f}_{V} \cdot Q}{u \cdot H \cdot W}
$$

From the last three expressions, VFs could be derived, and the resulting expressions, (10a), (10b) and (11), are in Table 2.

\section{Conflicts of Interest}

The authors declare no conflict of interest.

\section{References}

1. United States Environmental Protection Agency (USEPA). Risk Assessment Guidance for Superfund: Volume 1-Human Health Evaluation Manual (Part B, Development of Risk-based Preliminary Remediation Goals); EPA/540/R-92/003; USEPA: Washington, DC, USA, 1991.

2. European Commission. Technical Guidance Document on Risk Assessment in Support of Commission Directive 93/67/EEC on Risk Assessment for New Notified Substances, Commission Regulation (EC) No 1488/94 on Risk Assessment for Existing Substances and Directive 98/8/EC of the European Parliament and of the Council Concerning the Placing of Biocidal Products on the Market, Part I; European Commission Joint Research Centre: Brussels, Belgium, 2007.

3. Risk Assessment Information System (RAIS). Available online: http://rais.ornl.gov/cgibin/prg/PRG_search?select=chem (accessed on 27 March 2014).

4. Orejudo, E.; Mora, R.; Carnicero, V.; Martí, V.; López, D.; de Pablo, J.; Rovira, M. Development of risk-based contaminant reference concentration based on protection of human health for the sustainable use of groundwater. In Proceedings of the Consoil 2008, 10th International UFZ/TNO Conference on Soil-Water Systems, Milano, Italy, 3-6 June 2008.

5. American Society for Testing Materials. Standards Guide for Risk-Based Corrective Action Applied at Pretroleum Release Sites; E1739-95; ASTM: West Conshohocken, PA, USA, 1995.

6. Schwarzenbach, R.P.; Gschwend, P.M.; Imboden, D.M. Environmental Organic Chemistry, 2nd ed.; Wiley Interscience: New York, NY, USA, 2003.

7. Waterloo Hydrogeologic Inc. Risc WorkBench User's Manual: Human Health Risk Assessment Software for Contaminated Sites, v.4.0.; WHI: Waterloo, ON, Canada, 2001. 
8. Orejudo, E.; Mora, R.; Carnicero, V.; Martí, V.; López, D.; de Pablo, J.; Rovira, M. Simplified methodology for the sensitivity analysis of guideline values applied to water. D- Risks \& Impacts. In Proceedings of the Consoil 2008, 10th International UFZ/TNO Conference on Soil-Water Systems, Milano, Italy, 3-6 June 2008.

9. United States Environmental Protection Agency (USEPA). Water Quality Assessment, a Screening Procedure for Toxic and Conventional Pollutants in Surface and Ground Water (Part I); EPA/600/6-85/002a; USEPA: Washington, DC, USA, 1985.

10. Foster, S.A.; Chrostowski, P.C. Integrated Household Exposure Model for Use of Tap Water Contaminated with Volatile Organic Chemicals. In Proceedings of the 79th Annual Meeting of the Air Pollution Control Association, Minneapolis, MN, USA, 22-27 June 1986.

11. Carver, J.H.; Seigneur, C.S.; Block, R.M.; Miller, T.M. Comparison of Exposure Models for Volatile Organics in Tap Water. In Proceedings of Eighth Annual Hazmacon, Santa Clara, CA, USA, 15-18 April 1991.

12. Walden, J.T; Spence, L.R. Risk-Based BTEX Screening Criteria for a Groundwater Irrigation Scenario. J. Hum. Ecol. Risk Assess. 1997, 3, 699-722.

13. Risk Assessment Information System (RAIS). Available online: http://rais.ornl.gov/cgibin/tools/TOX_search?select=chem_spef (accessed on 30 May 2006).

14. GSI Environmental, GSI Chemical Properties Database. Available online: http://www.gsinet.com/es/publicaciones/gsi-chemical-database/list.html (accessed on 30 May 2006).

15. Andelman, J.B. Total Exposure to Volatile Organic Compounds in Potable Water. In Significance and Treatment of Volatile Organic Compounds in Water Supplies; Lewis Publishers: Chelsea, MI, USA, 1990; Chapter 20, pp. 485-504.

16. United States Environmental Protection Agency (USEPA). Volatilization Rates from Water to Indoor Air-Phase II; EPA 600/R-00/096; USEPA: Washington, DC, USA, 2000.

17. Lourencetti, C.; Grimalt, J.O.; Marco, E.; Fernandez, P.; Font-Ribera, L.; Villanueva, C.M.; Kogevinas, M. Trihalomethanes in chlorine and bromine disinfected swimming pools: Air-water distributions and human exposure. Environ. Int. 2012, 45, 59-67.

18. Howard, C.L. Volatilization Rates of Chemicals from Drinking Water to Indoor Air. Ph.D. Dissertation, The University of Texas, Austin, TX, USA, 1998.

19. Aggazzotti, G.; Fantuzzi, G.; Righi, E.; Predieri, G. Environmental and biological monitoring of chloroform in indoor swimming pools. J. Chromatogr. A 1995, 710, 181-190.

20. Aggazzotti, G.; Fantuzzi, G.; Righi, E.; Predieri, G. Blood and breath analyses as biological indicators of exposure to trihalomethanes in indoor swimming pools. Sci. Total Environ. 1998, 217, 155-163.

21. Fantuzzi, G.; Righi, E.; Predieri, G.; Ceppelli, G.; Gobba, F.; Aggazzotti, G. Occupational exposure to trihalomethanes in indoor swimming pools. Sci. Total Environ. 2001, 264, 257-265.

22. Caro, J.; Gallego, M. Assessment of exposure of workers and swimmers to trihalomethanes in an indoor swimming pool. Environ. Sci. Technol. 2007, 41, 4793-4798.

23. Moya, J.; Howard-Reed, C.; Corsi, R.L. Volatilization of chemicals from tap water to indoor air from contaminated water used for showering. Environ. Sci. Technol. 1999, 33, 2321-2327. 
24. Giardino, N.J.; Andelman, J.B. Characterization of the emission of trichloroethylene, chloroform and 1,2-dibromo-3-chloropropsne in a full-size experimental shower. J. Expo. Anal. Environ. Epidemiol. 1996, 6, 413-423.

25. Giardino, N.J.; Esmen, N.A.; Andelman, J.B. Modeling volatilization of trichloroethylene from a domestic shower spray: The role of drop-size distribution. Environ. Sci. Technol. 1992, 26, 1602-1606.

(C) 2014 by the authors; licensee MDPI, Basel, Switzerland. This article is an open access article distributed under the terms and conditions of the Creative Commons Attribution license (http://creativecommons.org/licenses/by/3.0/). 